\title{
Ethanol Effects on Intestinal Functions in Giardia lamblia-Infected Rats
}

\author{
Nidhi Mittal, ${ }^{1}$ Joginder Pal NagPaul, ${ }^{1}$ Safrun MahmooD ${ }^{2}$ \\ and Akhtar MAHMOOD ${ }^{1, *}$ \\ ${ }^{1}$ Department of Biochemistry, Panjab University, Chandigarh 160014, India \\ ${ }^{2}$ Department of Experimental Medicine and Biotechnology, \\ Post Graduate Institute of Medical Education and Research, \\ Chandigarh 160012, India
}

(Received October 16, 1998)

\begin{abstract}
Summary The effect of Giardia lamblia infection on D-glucose uptake and brush-border enzymes was studied in chronically ethanol-fed rats. Giardia lamblia trophozoites counts were significantly lower in the intestine of ethanol-fed rats than in the controls. Also, the $\mathrm{Na}^{+}$-dependent uptake of D-glucose and brush-border enzymes was significantly reduced ( $p<0.0001, p<0.01$, respectively) in the G. lamblia-infected rat intestine. There was no change in $\mathrm{Na}^{+}$-independent glucose uptake under these conditions. Levels of mRNA encoding $\mathrm{Na}^{+}$-dependent D-glucose transporter (SGLT1) and brush-border sucrase and lactase were reduced in $G$. lamblia-infected animals compared with those of the controls. However, the mRNA levels encoding these proteins in ethanol-fed and control animals were similar in rat intestine. These findings suggest that downregulation of SGLT1 and disaccharidases could be responsible for the observed D-glucose malabsorption and decrease in the activity of disaccharidases in G. lamblia infection.
\end{abstract}

Key Words: Giardia lamblia, ethanol feeding, malabsorption, sugar transport (D-glucose), disaccharidases

Giardia lamblia infection is a known cause of acute and chronic intestinal dysfunctions [1-3]. However, the factors augmenting this parasitic infection are not known. The prerequisite for colonization of the parasite in the intestine is the adhesion of trophozoites to the epithelial cell surface [4]. It is amply recognized that surface oligosaccharides are implicated in the adhesion of microflora to the

* To whom correspondence should be addressed. 
cell surface [5]. The surface of Giardia trophozoites contains a carbohydrate binding protein that recognizes $N$-acetylglucosamine/sialic acid; thus, lectinmediated receptor binding has been proposed as the mechanism of attachment of this protozoa to the intestinal epithelium $[6,7]$. We previously reported that chronic ethanol feeding markedly altered the glycosylation pattern in the rat intestine [8]. The sialic acid content of brush borders was markedly enhanced with a concomitant decrease in fucose levels in response to ethanol administration [8]. The observed glycosylation pattern in ethanol-fed animals is similar to that observed in suckling rats [9], which are more prone to Giardia infection [10]. Thus to examine the role of ethanol ingestion in the pathogenesis of giardiasis, the present studies were undertaken to investigate the effect of $G$. lamblia infection on intestinal functions in chronically ethanol-fed rats. In addition, the mRNA levels encoding the $\mathrm{Na}^{+}$-dependent D-glucose transporter (SGLT1) and brush-border sucrase and lactase enzymes were also analyzed under these conditions.

\section{MATERIALS AND METHODS}

Animals and treatments. Male Wistar rats (30-40 g body wt) were used. Animals were divided into two groups. The animals in group I were administered orally $1 \mathrm{ml}$ of $30 \%$ ethanol daily via a Ryle's tube for 4 weeks. Rats in group II received an isocaloric solution of glucose.

G. lamblia cysts obtained from human stool were purified on a sucrose gradient [1.1]. Inoculum dose of 10,000 cysts/animal in $0.2 \mathrm{ml}$ of normal saline was given orally via a Ryle's tube to half of the unanesthetized animals in both group I (ethanol fed) and group II (isocaloric glucose fed).

Preparation of brush-border membranes. Overnight fasted rats were sacrificed under ether anesthesia. Starting from the ligament of Treitz, $20-25 \mathrm{~cm}$ of intestine was removed and thoroughly washed with ice-cold saline. Brush-border membrane (BBM) was isolated and purified following the method of Schmitz et al. [12].

Enzyme assays. Brush-border sucrase or lactase activities were assayed following the method of Dahlquist [13]. Alkaline phosphatase and leucine aminopeptidase activities were determined according to the method of Bergmeyer [14] and Naftalin et al. [15], respectively. Protein was estimated by the method of Lowry et al. [16], with bovine serum albumin used as the standard.

Quantification of trophozoites. The small intestine of the infected rats was removed on day 10 postinfection and flushed with a fixed amount of normal saline. The trophozoites were counted in a hemocytometer, and the results were expressed as total number of trophozoites in the drained fluid.

$D$-Glucose uptake measurement. The uptake of D-glucose was studied by use of radiolabeled [U- ${ }^{14} \mathrm{C}$ ] D-glucose, as described previously [17]. Everted intestinal segments $(0.3-0.5 \mathrm{~cm})$ were incubated for $5 \mathrm{~min}$ at $37^{\circ} \mathrm{C}$ in $5 \mathrm{ml}$ of oxygenated $(95 \%$ $\left.\mathrm{O}_{2}-5 \% \mathrm{CO}_{2}\right)$ Tris-maleate buffer $(120 \mathrm{mM} \mathrm{NaCl}$ or choline chloride, $1.21 \mathrm{mM}$ 
$\mathrm{MgSO}_{4}, 0.63 \mathrm{mM} \mathrm{CaCl}_{2}$ and Tris-maleate solution of $\mathrm{pH} 5.5$ and 7.2 to bring the final osmolarity to $300 \mathrm{mOsm}$ ). The buffer contained $5 \mathrm{~mm} \mathrm{D}$-glucose with a trace amount of $\left[\mathrm{U}-{ }^{14} \mathrm{C}\right]$ glucose (sp. activity: $160 \mathrm{mCi} / \mathrm{mmol}$ ). After incubation, tissues were gently blotted on filter paper, weighed, and digested in $10 \% \mathrm{KOH}$. The radioactivity was determined in an LKB Reck Beta Scintillation counter. The uptake rate was corrected for the extracellular space measured with $\left[{ }^{3} \mathrm{H}\right]$ inulin and expressed as $\mu \mathrm{mol}$ glucose $/ 5 \mathrm{~min} / \mathrm{g}$ tissue.

$R N A$ preparation and Northern blot analysis. Total RNA from the intestine frozen in liquid $\mathrm{N}_{2}$ was isolated by the guanidinium thiocyanate method [18] and resolved on formaldehyde-agarose gels [19]. The denatured RNA was transferred onto nylon membranes (zeta probe, Bio-Rad, Hercules, CA) by a capillary transfer method using $50 \mathrm{~mm} \mathrm{NaOH}$ [20]. The transferred RNA was fixed on membranes by exposing the membrane carrying RNA to a source of low doses of ultraviolet irradiation (strata-UV crosslinker). Prehybridization of the membrane containing immobilized RNA was carried in SDS formamide buffer at $42^{\circ} \mathrm{C}$ for $4 \mathrm{~h}$ [20]. Simultaneously the oligonucleotide probes were added to the pre-hybridization sealed bags and hybridized for $20-24 \mathrm{~h}$ at $42^{\circ} \mathrm{C}$. After hybridization, the membranes were washed with $2 \times \mathrm{SSC}, 0.1 \% \operatorname{SDS}\left(20 \mathrm{~min}\right.$, each three times) at $42^{\circ} \mathrm{C}$ and autoradiographed by exposing the filter to X-ray film (Kodak XAR-2) for 3-5 days at $-70^{\circ} \mathrm{C}$ with an intensifying screen. The antisense oligonucleotide probes complementary to mRNA were used. The oligonucleotide probes used were $5^{\prime}$ 249-273 for $\mathrm{Na}^{+}$-glucose transporter [21], 5' 13-33 for lactase [22], and 5' 92-119 for sucrase [23]. $\beta$-Actin probe was used as a marker of a housekeeping gene.

Statistical analysis of data was done by Student's $t$-test and analysis of variance (ANOVA).

\section{RESULTS}

G. lamblia-infected animals manifested watery diarrhea, which was maximal on day 10 postinfection. The trophozoites counted in the intestinal flush out of these animals revealed a high degree of infection in both glucose-fed and ethanolfed rats exposed to G. lamblia (Table 1). Interestingly, the number of G. lamblia

Table 1. Intestinal uptake of D-glucose in control and ethanol-fed rats infected with G. lamblia.

\begin{tabular}{|c|c|c|c|c|}
\hline \multirow{2}{*}{ Parameter } & \multicolumn{2}{|c|}{ Control } & \multicolumn{2}{|c|}{ Ethanol fed } \\
\hline & (-) G. lambli & $(+)$ G. lamblia & (-) G. lamblia & $(+)$ G. lamblia \\
\hline Trophozoite counts $\left(\log _{10}\right)$ & Nil & $8.39 \pm 3.74$ & Nil & $7.26 \pm 2.58 * * *$ \\
\hline \multicolumn{5}{|c|}{ D-Glucose uptake ${ }^{\#}(\mu \mathrm{mol}$ glucose $/ 5 \mathrm{~min} / \mathrm{g}$ tissue $w \mathrm{t})$} \\
\hline$(+) \mathrm{Na}^{+}$ & $5.74 \pm 0.98$ & $3.65 \pm 0.35 * * * a$ & $6.37 \pm 0.76$ & $4.15 \pm 1.47 * * * \mathrm{~b}$ \\
\hline$(-) \mathrm{Na}^{+}$ & $2.37 \pm 0.20$ & $2.02 \pm 0.61$ & $2.55 \pm 0.23$ & $3.31 \pm 0.81$ \\
\hline
\end{tabular}

Values are mean \pm SD of 4-6 observations in each group. Significant differences ${ }^{* *} p<0.001$

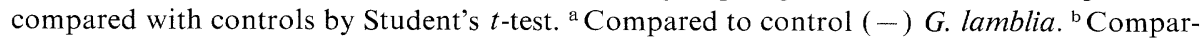
ed to ethanol (-) G. lamblia. "Significant according to ANOVA.

Vol. 26, No. 1, 1999 
Table 2. Effect of ethanol feeding and G. lamblia infection on brush-border enzymes in rat intestine.

\begin{tabular}{lcllll}
\hline \multirow{2}{*}{ Enzyme } & \multicolumn{2}{c}{ Control } & & \multicolumn{2}{c}{ Ethanol fed } \\
\cline { 2 - 3 } \cline { 5 - 6 } & $(-)$ G. lamblia $(+)$ G. lamblia & & $(-)$ G. lamblia & $(+)$ G. lamblia \\
\hline Sucrase $^{*}$ & $1.13 \pm 0.19$ & $0.26 \pm 0.09^{* * * a}$ & & $0.67 \pm 0.06$ & $0.28 \pm 0.07^{* * * a, b}$ \\
Lactase $^{\#}$ (units/g protein) & $77.4 \pm 10.1$ & $61.7 \pm 11.0^{* \mathrm{a}}$ & & $81.9 \pm 11.1$ & $65.3 \pm 7.08^{* \mathrm{a}, \mathrm{b}}$ \\
Alkaline phosphatase $^{*}$ & $1.10 \pm 0.27$ & $0.38 \pm 0.01^{* * \mathrm{a}}$ & & $0.58 \pm 0.07^{* * \mathrm{a}}$ & $0.50 \pm 0.14^{* * \mathrm{a}}$ \\
Leucine aminopeptidase $^{\#}$ & $0.45 \pm 0.10$ & $0.23 \pm 0.02^{* * \mathrm{a}}$ & & $0.34 \pm 0.04$ & $0.24 \pm 0.11^{* \mathrm{a}}$ \\
\hline
\end{tabular}

Values are mean \pm SD of 4-6 observations as units $/ \mathrm{mg}$ protein. 1 unit is equal to $1 \mu \mathrm{mol}$ of substrate hydrolyzed per minute under standard assay conditions. Significant differences ${ }^{*} p<0.05 ;{ }^{* *} p<0.01 ;{ }^{* * *} p<0.001$ compared with controls by Student's $t$ test. ${ }^{a}$ Compared to

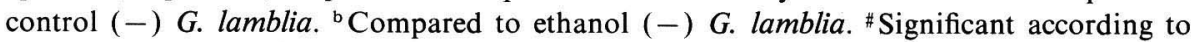
ANOVA.
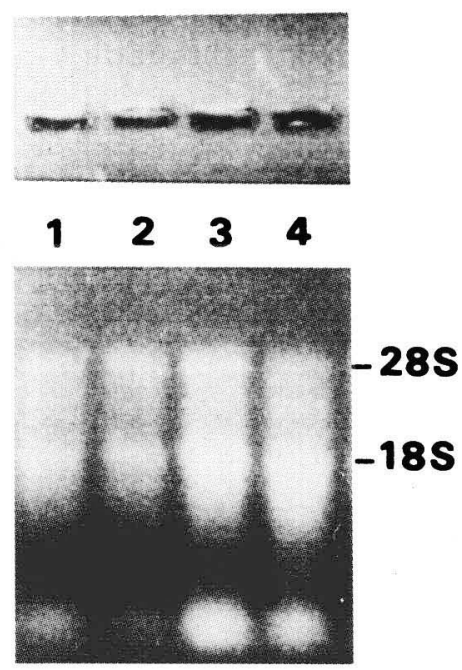

(a)

\section{B-ACTIN}

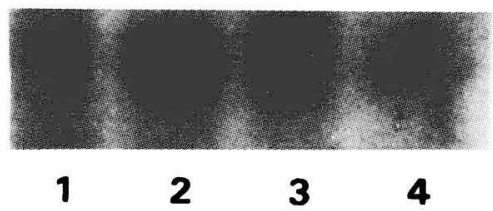

(b)

Fig. 1. Northern blot analysis of mRNA by agarose gel electrophoresis (a). Total RNA from small intestine of control and ethanol-fed rats infected with G. lamblia was obtained by guanidinium thiocyanate and phenol-chloroform extraction and analyzed on $1 \%$ agarose gels stained with ethidium bromide. Northern blot analysis of mRNA encoding $\beta$-actin (b). Each lane was loaded with $10 \mu \mathrm{g}$ of total RNA. Lane 1, Control (-) G. lamblia; lane 2, control (+) G. lamblia; lane 3, ethanol-fed (-) G. lamblia and lane 4, ethanol-fed (+) G. lamblia. 
trophozoites was significantly lower $(p<0.001)$ in the ethanol-fed rats than in the glucose-fed controls (group I). There was no change in $\mathrm{Na}^{+}$-independent D-glucose uptake $(2.02-3.31 \mu \mathrm{mol}$ glucose $/ 5 \mathrm{~min} / \mathrm{g}$ tissue in ethanol-or fed $G$. lambliainfected animals compared with that in the uninfected controls. Feeding of ethanol to rats did not affect $\mathrm{Na}^{+}$-dependent D-glucose uptake (5.74-6.37 $\mu$ mol glucose $/ 5$ $\mathrm{min} / \mathrm{g}$ tissue from the intestine. However, $\mathrm{Na}^{+}$-dependent sugar uptake was significantly $(p<0.001)$ reduced in Giardia-infected rats compared with that in uninfected controls (Table 1).

Ethanol feeding for 4 weeks to rats significantly reduced the activities of sucrase, alkaline phosphatase (AP), and leucine amino peptidase (LAP) compared with the control levels (group I). However, there was no change in lactase activity under these conditions. The activities of brush-border sucrase, lactase, AP, and LAP were markedly reduced in $G$. lamblia-infected animals fed isocaloric glucose or ethanol compared with those of non-infected animals (Table 2).

As shown in Fig. 1, there was no change in mRNA levels encoding $\beta$-actin used as a housekeeping gene, in the control, ethanol-treated or Giardia-infected animals. Northern blot analysis, however, revealed a marked decrease in mRNA levels. encoding sucrase, lactase, and $\mathrm{Na}^{+}$-dependent D-glucose transporter (SGLT1) in G. lamblia-infected rat intestine compared with the levels for the

\section{SUCRASE}
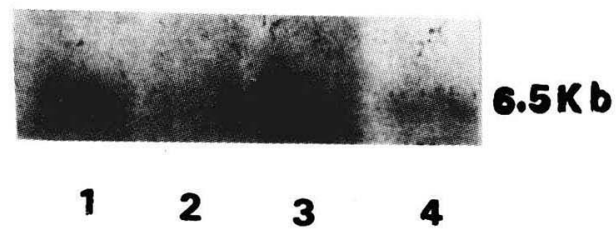

(a)

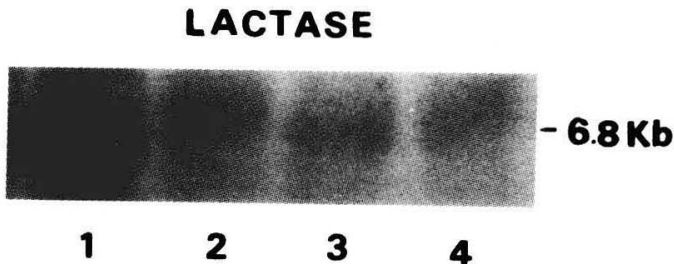

(b)

Fig. 2. Northern blot analysis of mRNA encoding brush-border sucrase (a) and lactase (b) in control and ethanol-fed rats infected with $G$. lamblia. Each lane contained $10 \mu \mathrm{g}$ of intestinal RNA. Blots were hybridized with radiolabeled oligonucleotide probes. Autoradiography was carried using X-ray film (Kodak XAR-2) and intensifying screens at $-70^{\circ} \mathrm{C}$ for 3-5 days. Lane 1 , control (-) G. lamblia; lane 2, control ( + ) G. lamblia; lane 3, ethanol-fed (-) G. lamblia, and lane 4, ethanol-fed (+) G. lamblia. 


\section{GLUCOSE TRANSPORTER}

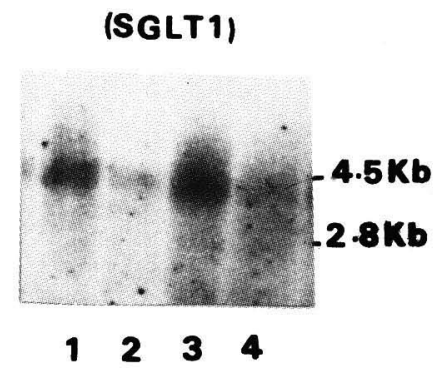

Fig. 3. Northern blot analysis of mRNA encoding $\mathrm{Na}^{+}$-dependent D-glucose transporter in control and ethanol-fed rats infected with $G$. lamblia. Each lane contained $10 \mu \mathrm{g}$ of intestinal RNA from small intestine. Blots were hybridized with radiolabeled oligonucleotide probe. Autoradiography was carried out using X-ray film (Kodak XAR-2) and intensifying screens at $-70^{\circ} \mathrm{C}$ for 3-5 days. Lane 1 , control (-) G. lamblia; lane 2, control (+) G. lamblia; lane 3, ethanol-fed (-) G. lamblia and lane 4, ethanol-fed (+) G. lamblia.

control group. However, the mRNA levels were essentially similar in ethanol-fed and control (group I) rats. Levels of mRNA encoding disaccharidases or SGLT1 cotransporter in Giardia-infected animals were essentially similar to those in ethanol-fed, Giardia-exposed animals. Thus ethanol administration per se did not affect the mRNA levels of the enzyme and the glucose- $\mathrm{Na}^{+}$co-transporter in the rat intestine. But $G$. lamblia infection induced a significant decrease in the amounts of the mRNA transcripts. Radiolabeled probes of sucrase and lactase hybridized with $6.5-\mathrm{kb}$ (Fig. 2a) and 6.8-kb (Fig. 2b) transcripts, respectively. The SGLT1 probe hybridized to two transcripts of $4.5-\mathrm{kb}$ and $2.8-\mathrm{kb}$ fragments (Fig. 3). The $2.8-\mathrm{kb}$ transcript was only of faint intensity. This is due to the fact that the two mRNA fragments contain the same coding region with different length of the $3^{\prime}$ non-coding region [24]. Therefore, the observed decrease in brush-border sucrase and lactase activity as well as in D-glucose uptake in G. lamblia-infected rat intestine is a consequence of the down-regulation of the gene expression of these proteins.

\section{DISCUSSION}

The results presented here indicate lower levels of G. lamblia trophozoites in the intestine of ethanol-fed rats than in that of the control animals. Farthing et al. [7] suggested the presence of WGA-like lectin on the surface of G. lamblia cyst to be responsible for the adhesion of the parasite to the luminal surface of enterocytes.

Thus, the observed decrease in G. lamblia counts in ethanol-fed animals could be attributed to a modified glycosylation pattern of enterocytes under these 
conditions [25]. The low levels of the parasite in the ethanol-fed intestine, however, can not be due to a direct effect of ethanol on the Giardia trophozoites, for during the period of infection, the animals were not exposed to ethanol. The indirect effects of the ethanol ingestion, as a consequence of changes in biliary and pancreatic secretions in the gut, however, can not be ruled out. But, nevertheless, the finding indicating lower counts of Giardia trophozoites in ethanol-fed rats than in those given isocaloric glucose is interesting and needs further investigation.

The present data also indicate that $G$. lamblia infection in both the control and chronically ethanol-fed animals induced a similar decrease in D-glucose uptake and brush-border enzymes, although there was a significant difference in the degree of parasitemia in the two groups. The observed decrease in sucrase, lactase, AP, and LAP activities in G. lamblia-infected rats was similar to that reported earlier [26]. A similar decrease in D-glucose uptake from the intestine in animals exposed to G. lamblia has also been reported [26]. Both giardiasis and ethanol feeding are known to produce morphological alterations in the intestine $[27,28]$. The mechanism of intestinal malabsorption in giardiasis is unknown, although a number of hypotheses have been advanced to explain this phenomenon, such as (a) mechanical obstruction of the villus surface by abundance of the G. lamblia trophozoites [27]; (b)damage of the intestinal mucosa as a sequel to the parasitic infection; (c) presence of bacterial overgrowth or fungal growth; (d) invasion of the epithelial cells by Giardia infection; (e) changes in the turnover rate of epithelial cells; (f) enhanced secretion of mucus or mucoid substances in the presence of parasites, as has been observed in humans and in experimental models [29]. It is likely that a combination of these factors could be implicated in the pathogenesis of intestinal dysfunctions in giardiasis.

In the present studies, low levels of mRNA encoding for D-glucose transporter and brush-border sucrase and lactase activities were demonstrated in the $G$. lamblia-infected rat intestine. However, there was no change in mRNA levels of these proteins in chronically ethanol-fed rats. This apparently indicates that the underlying mechanisms of malabsorption in giardiasis and chronic alcoholism are distinct. Presumably, ethanol feeding affects the cell morphology leading to aberration of surface enterocytes. However, G. lamblia infection induces malabsorption by affecting the expression of brush-border disaccharidases and sugar transporter proteins. The SGLT1-specific oligonucleotide probe hybridized with 4.5-kb and 2.8-kb fragments of intestinal mRNA. Coady et al. [30] earlier reported homology between cDNA clones of $\mathrm{Na}^{+}$-glucose cotransporter in human and several animal species. The rabbit intestinal Na-glucose cotransporter cDNA used by them hybridized strongly with $4.5-\mathrm{kb}$ and weakly with $2.8-\mathrm{kb}$ mRNA transcripts. This is identical to the findings described herein. This could be an additional mechanism of intestinal malabsorption in this infection.

In conclusion, the present findings indicate that $G$. lamblia counts were decreased in intestine of ethanol-fed rats; which is presumably due to alteration in glycosylation pattern in intestinal epithelium in these animals [8]. G. lamblia 
infection induced a marked decrease in D-glucose uptake and in the activities of various brush-border enzymes, which was as a consequence of down-regulation of the expression of mRNA encoding these proteins. Ethanol feeding, however, had no effect on the expression of these proteins in the rat intestine.

We are grateful to Department of Parasitology, PGIMER, Chandigarh (India) for providing the stool samples of patients suffering from giardiasis. Financial assistance from University Grants Commission (UGC) and Indian Council of Medical Research (ICMR), New Delhi (India) to carry out the present investigation is gratefully acknowledged.

\section{REFERENCES}

1. Anita, F.P., Desai, H.G., and Baker, V.V. (1966): Giardia in adults incidence, symptomatology and absorption studies. Indian J. Med. Sci., 20, 477.

2. Blanco-Robaso, E., Fergosa, A.J., Castaneda, C.E., and Sagaro, E.C. (1975): Malabsorption due to Giardia lamblia. Rev. Cubana Paediatr., 47, 247-251.

3. Ridley, M.J., and Ridley, D.S. (1979): Serum antibodies and jejunal histology in giardiasis associated with malabsorption. J. Clin. Pathol., 29, 30-35.

4. Farthing, M.J.G. (1985): Receptors and recognition mechanisms in intestinal infection. Trans. R. Soc. Trop. Med. Hyg., 79, 569-576.

5. Kim, Y.S., Morita, A., Mirura, S., and Siddiqui, B. (1984): Structure of glycoconjugates of intestinal membranes: Role in bacterial adherence, in Attachment of Organisms to the Gut Mucosa, Vol. II, ed. by Boedeke, E.C., CRC Press, Inc., Boca Raton, pp. 99-109.

6. Lev, B., Ward, H., Keusch, G.T., and Pereira, M.E. (1986): Lectin activation in Giardia lamblia by protease: A novel host-parasite interaction. Science, 232, 71-73.

7. Farthing, M.J.G., Pereira, M.E.A., and Keusch, G.T. (1986): Description and characterization of a surface lectin from Giardia lamblia. Infect. Immunol., 51, 661-667.

8. Kaur, J., Jaswal, V.M.S., Nagpaul, J., and Mahmood, A. (1992): Chronic ethanol feeding and microvillus membrane glycosylation in normal and protein malnourished rat intestine. Nutrition, 8, 338-342.

9. Jaswal, V.M.S., Babbar, H., and Mahmood, A. (1988): Changes in sialic acid and fucose contents of enterocytes across the crypt-villus axis in development of rat intestine. Biochem. Med. Metab. Biol., 39, 105-110.

10. Kanwar, S., Samra, H., Ganguly, N.K., and Mahajan, R.C. (1986): Comparative evaluation of Giardia lamblia infection in mouse and rat. Indian J. Med. Res., 84, 577-581.

11. Roberts-Thomson, I.C., Stevens, D.P., Mahmood, A., and Warren, K.S. (1976): Giardiasis in mouse-An animal model. Gastroenterology, 71, 571-576.

12. Schmitz, J., Presier, H., Maestracci, D., Ghosh, B.K., and Crane, R.K. (1976): Purification of the human intestinal brush border membranes. Biochim. Biophys. Acta, 323, 98-112.

13. Dahlquist, A. (1964): Method for the assay of intestinal disaccharidases. Anal. Biochem., 7 , $18-25$.

14. Bergmeyer, M.V.C. (1963): Method of Enzymatic Analysis, Academic Press, New York, Vol. 40, pp. 783-785.

15. Naftalin, L., Sexton, M., Whitaker, J.F., and Tracey, D. (1969): A routine procedure for estimating serum $\gamma$-glutamyltranspeptidase activity. Clin. Chim. Acta, 26, 293-296.

16. Lowry, O.H., Rosebrough, N.J., Farr, A.L., and Randall, R.J. (1951): Protein measurement with the Folin phenol reagent. J. Biol. Chem., 193, 265-275.

17. Alvarado, F., and Mahmood, A. (1974): Co-transport of organic solute and sodium ions in the small intestine; a general models of amino acid transport. Biochemistry, 13, 2882-2890.

18. Chomczynski, P., and Sacchi, N. (1986): Single step method of RNA isolation by acid guanidinium thiocyanate-phenol-chloroform extraction. Anal. Biochem., 162, 156-159.

19. Lehrach, H., Diamond, D., Wozney, J.M., and Boedtker, H. (1977): RNA molecules weight 
determinations of gel electrophoresis under denaturing conditions, a critical examination. Biochemistry, 16, 4743-4745.

20. Reed, K.C., and Mann, D.A. (1958): Rapid transfer of RNA from agarose gels to nylon membranes. Nucleic Acids Res., 13, 7207.

21. Hediger, M.A., Coady, M., Ikeda, T., and Wright, E.M. (1987): Expression cloning on cDNA sequencing of $\mathrm{Na}^{+}$/glucose transporter. Nature, 330, 379-381.

22. Mantei, N., Villa, M., Enzler, T., Walker, H., Bell, W., Jame, P., Hunziker, W., and Semenza, G. (1988): Complete primary structure of human and rabbit lactase phlorizine hydrolase. EMBO J., 7, 2705-2713.

23. Hanziker, W., Spiess, M., Semenza, G., and Lodish, H.F. (1986): Sucrose isomaltase complex primary structure membrane orientation and evaluation of stalked intrinsic brush border protein. Cell, 46, 227-234.

24. Hediger, M.A., Turk, E., and Wright, E.M. (1989): Biosynthesis of the cloned intestinal sodium/glucose co-transporter. Proc. Natl. Acad. Sci. U.S.A., 86, 5748-5752.

25. Kaur, J., Gupta, R., Kaur, M., Nagpaul, J.P., and Mahmood, A. (1994): Effect of chronic ethanol administration on intestinal microvillus membrane glycosylation in rats fed rat pellet diet and protein-rich diet. J. Clin. Biochem. Nutr., 16, 133-142.

26. Anand, B.S., Mahmood, A., Ganguly, N.K., Rehani, M.M., Dilawari, J.B., and Mahajan, R.C. (1982): Transport studies and enzyme assays in mice infected with human Giardia lamblia. Trans. R. Soc. Trop. Med. Hyg., 76, 616-619.

27. Phillip, D., and Smith, M.D. (1985): Pathophysiology and immunology of giardiasis. Annu. Rev. Med., 36, 295-307.

28. Beck, I.T., and Dinda, P.K. (1981): Acute exposure of small intestine of ethanol. Effects on morphology function. Dig. Dis. Sci., 26, 817-828.

29. Poley, J.R., and Rosenfield, S. (1982): Malabsorption in giardiasis: Presence of a luminal barrier (mucoid pseudomembrane). A scanning and transmission electron microscopic study. J. Pediatr. Gastroenterol. Nutr., 1, 63-80.

30. Coady, M.J., Pajor, A.M., and Wright, E.M. (1990): Sequence homologies among intestinal and renal $\mathrm{Na}^{+} /$glucose cotransporters. Am. J. Physiol., 259, C605-610. 